\title{
Seabed preparation design and construction for the Malampaya Phase 3 Depletion Compression Platform
}

\author{
Jasvinder Opkar \\ Arup Pty Ltd, Brisbane, Australia
}

Leon Lorenti

Arup Pty Ltd, Perth Australia

Andrew Grime

Arup Pty Ltd, Perth Australia

\begin{abstract}
The Depletion Compression Platform (DCP) was conceived by Shell Philippines Exploration B.V. (SPEX) to provide additional gas compression to account for the future expected decrease in well pressure from the Malampaya field. The Malampaya project is very important to the ongoing prosperity of the Philippines, with the exported gas feeding three power stations which have a combined output providing up to $45 \%$ of the power needs of Luzon, the largest and most populous island in the Philippines.
\end{abstract}

During the concept phase of the project SPEX selected Arup's ACE Gravity Base Structure (GBS) as the substructure solution for the DCP. The DCP substructure was designed to be supported on four linked regular hexagonal pad footings with dimensions of $18 \mathrm{~m} \times 20.8 \mathrm{~m} \mathrm{x} 4 \mathrm{~m}$ deep. These pad footings were founded on individually prepared support pads composed of engineered rock fill material of approximately $1 \mathrm{~m}$ in thickness.

It is standard practice to include a larger sized scour blanket around the footing perimeter to prevent local erosion, undermining and loss of support. However, during design development we were challenged by the project team to omit this element altogether by selecting a founding engineered rock fill material which was itself suitably sized to prevent scour.

Given there is no analytical approach available to accurately determine the local flow enhancement around the apices of the individual hexagonal pad footings at seabed level, Computational Fluid Dynamics (CFD) modelling and Wave Tank Testing (WTT) were employed. The effect of the existing adjacent Concrete Gravity Structure (CGS) was also considered as part of this assessment. The results of the CFD modelling and WTT was used to calculate a minimum size range for the engineered rock fill which is capable of resisting the enhanced flow velocities in the 100 -year return period cyclonic storm event.

Following calculation of the required size of engineered rock fill material, this information was presented to the potential seabed preparation Contractors for agreement on the achievable surface profile. The agreed local surface profile of the seabed preparation support pads was then used to assess the structural performance of the pad footing. Once structural performance was shown to be adequate this confirmed that the dedicated larger sized scour protection layer could be omitted. This yielded savings to the project by minimising material procurement, vessel modification and offshore working time.

The construction of the seabed preparation support pads using the larger sized engineered rock fill was performed successfully within the tolerances established and agreed through early consultation with the potential seabed preparation Contractors.

\section{INTRODUCTION}

This article presents summary details of the innovative scour protection design performed for the Malampaya Depletion Compression Platform (DCP), which was installed 200 nautical miles south west of Manila, The Philippines, adjacent and bridge linked to the existing Shallow Water Platform (SWP) at the Malampaya site.

The DCP was conceived by Shell Philippines Exploration B.V. (SPEX) to provide additional gas compression to account for the future expected decrease in well pressure from the Malampaya field. Once installed, the DCP will operate to maintain an acceptable rate of flow through the Gas Export Pipeline (GEP) until the end of field life.

The Malampaya project is very important to the ongoing prosperity of The Philippines, with the gas supplied through the GEP feeding three power stations with a maximum generating capacity of 2,700 MW. The combined output from these three power 
stations provide up to $45 \%$ of the power needs of Luzon, the largest and most populous island in The Philippines. Sustaining the use of natural gas for power generation offsets the potential increase in reliance on coal and fuel oil.

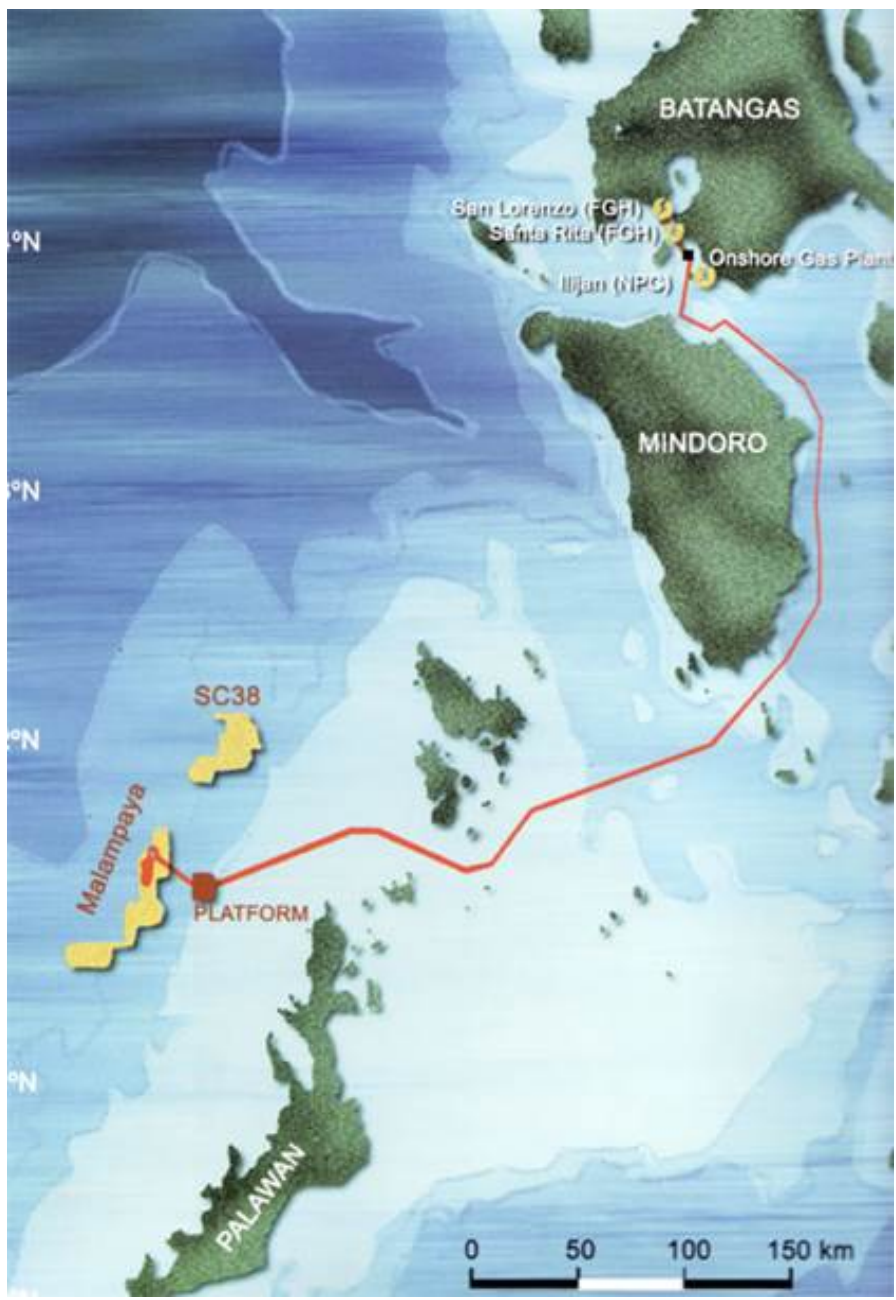

Figure 1. Location of the Malampaya field, Malampaya platforms and the Gas Export Pipeline route to shore

\section{GROUND CONDITIONS}

Ground conditions at the DCP site were assessed from two detailed ground investigations, the first undertaken in 1997 for the existing SWP and the second for the DCP in August and September 2011.

The DCP site is located to the northwest of Palawan Island in the West Philippine Sea. The site is situated in an area where a significant thickness of calcareous soils and rocks have deposited in a relatively stable geological environment.

The natural seabed levels under the DCP footprint were assessed to vary from $39 \mathrm{~m}$ to $43 \mathrm{~m}$ below lowest astronomical tide (LAT). A relatively flat area exists over the eastern half of the DCP footprint, with a ridge feature up to $4 \mathrm{~m}$ in height crossing the western half.

The generalised stratigraphy for the "flat" portion of the site consisted of $0.5 \mathrm{~m}$ to $6 \mathrm{~m}$ of carbonate sand overlying $3 \mathrm{~m}$ to $15 \mathrm{~m}$ of reef limestone, under- lain by approximately $35 \mathrm{~m}$ of calcarenite. A similar sequence of reef limestone, calcarenite and interbedded carbonate rocks underlies this thick calcarenite layer.

\section{DCP STRUCTURE}

The DCP consists of a sealed barge structure which is rigidly connected to four cylindrical legs, each of which is supported on an individual hexagonal pad footing. The pad footings are linked by a horizontal truss which accommodates small differences in the founding level of each pad footing while permitting horizontal load share.

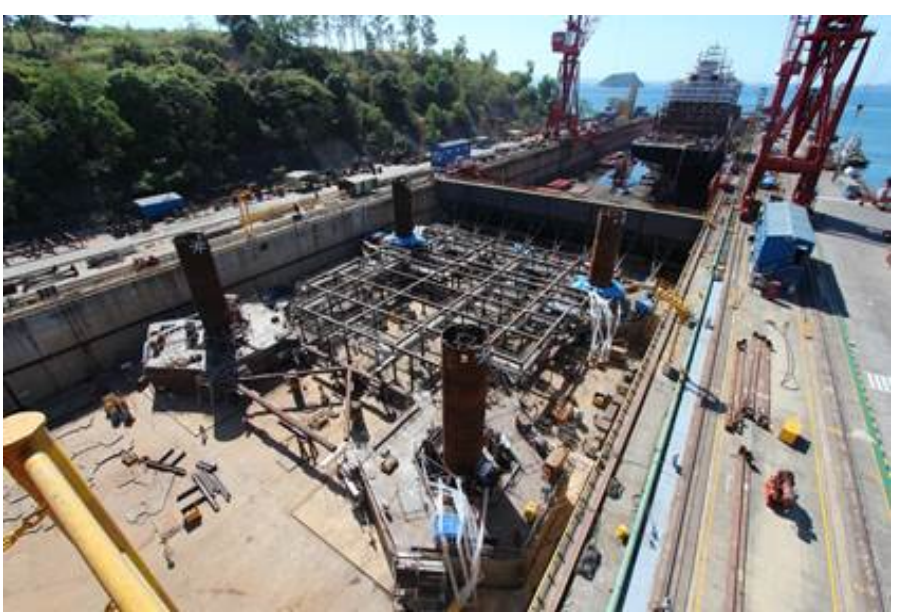

Figure 2. Truss-linked pad footing foundation system under construction

\section{PRELIMINARY DESIGN}

\subsection{Design Concept}

The original design concept for the Malampaya project was for the placement of four, nominally $1 \mathrm{~m}$ thick seabed preparation support pads consisting of a granular fill over the natural seabed surface. These seabed preparation support pads were devised to form a layer of controlled stiffness and surface quality for placement of the pad footings of the DCP.

Once the ground conditions were established it was deemed necessary to remove the reef limestone ridge feature on the western side of the DCP footprint in order to match the level of the adjacent "flat area" over the eastern half of the DCP footprint at approximately $-43 \mathrm{mLAT}$.

\subsection{Design requirements}

\subsubsection{General arrangement}

The general arrangements of the DCP pad footing foundation system (hexagonal pads) and seabed preparation support pads (circular) are illustrated in Figure 3. The circular pads are $45 \mathrm{~m}$ in diameter which includes a $3 \mathrm{~m}$ wide $3: 1$ slope to the seabed. 


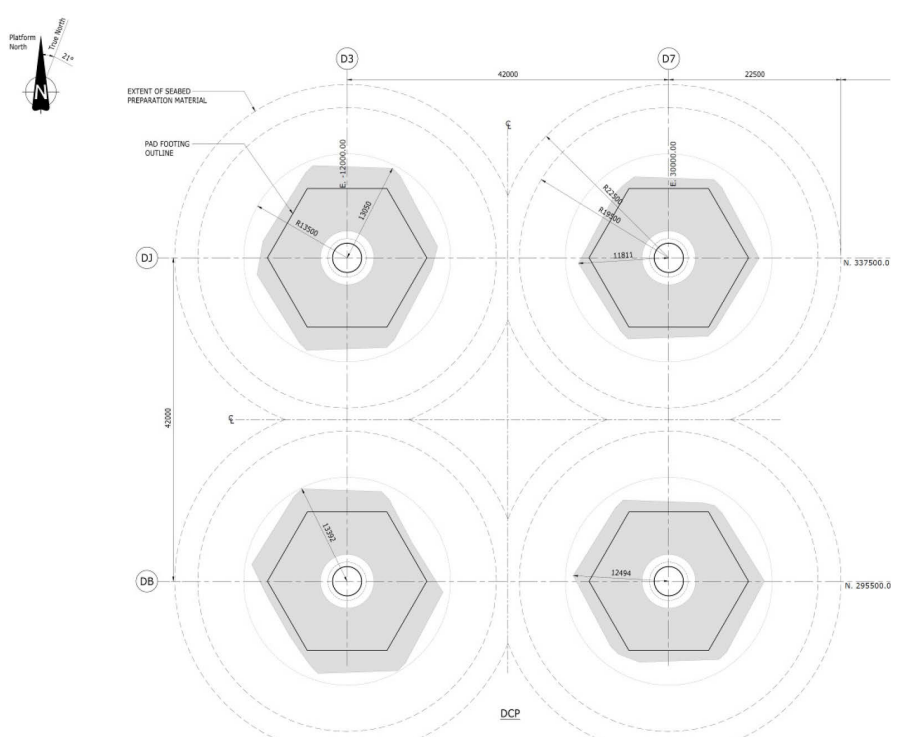

Figure 3. Pad footing general arrangement on seabed

\subsubsection{Design life}

The design life for the DCP, including the seabed preparation support pads and scour protection, is 30 years.

\subsubsection{Return Periods}

The scour protection layer for the seabed preparation material was designed to be able to resist a 10-year return period cyclonic event without damage, both with or without the DCP in place. The latter case was introduced to cover the critical temporary construction condition should there be an unforeseen delay in the platform installation.

In addition, during a 100 -year return period cyclonic event, with the DCP in place, the scour protection was designed such that the overall integrity of the seabed preparation support pads would not be compromised such that any damage to the seabed preparation could be readily repaired.

\subsection{Design parameters}

\subsubsection{Water depth}

The water depth at the site is approximately 43 mLAT.

\subsubsection{Wave}

The Malampaya platform is located in an area subjected to cyclones (typhoons). The omni-directional cyclonic wave data for the in-place condition are summarized in Table 1.

Table 1. Wave data

\begin{tabular}{lll}
\hline Parameters & 10-year & 100-year \\
\hline Significant wave height, $\mathrm{H}_{\mathrm{s}}(\mathrm{m})$ & 6.6 & 9.1 \\
Maximum wave height, $\mathrm{H}_{\max }(\mathrm{m})$ & 11.3 & 15.4 \\
Peak period, $\mathrm{T}_{\mathrm{p}}(\mathrm{s})$ & 14.4 & 16.9 \\
\hline
\end{tabular}

\subsubsection{Flow Current}

The omni-directional all-year flow current data for the in-place condition are summarized in Table 2.

Table 2. Current data

\begin{tabular}{lll}
\hline Parameters $(\mathrm{m} / \mathrm{s})$ & 10 -year & 100 -year \\
\hline Surface & 1.71 & 2.12 \\
80\% water depth & 1.64 & 2.03 \\
60\% water depth & 1.54 & 1.91 \\
40\% water depth & 1.42 & 1.77 \\
20\% water depth & 1.24 & 1.54 \\
10\% water depth & 1.08 & 1.34 \\
5\% water depth & 0.94 & 1.16 \\
2\% water depth & 0.78 & 0.97 \\
Bottom & 0.49 & 0.61 \\
\hline
\end{tabular}

The $2 \%$ water depth is approximately $0.9 \mathrm{~m}$ above the seabed and hence close to the design level of the underside of the DCP pad footings, which are founded on nominally $1 \mathrm{~m}$ high seabed preparation support pads. This water depth was used to determine the total flow velocity for scour assessment.

\subsubsection{Combined Seabed Current}

The design current magnitude on seabed was determined by combining the wave induced current and the flow current. The Fenton's Fourier series analysis method was used to do this, which forms a part of the Coastal Engineering Design and Analysis Software (CEDAS) package.

The values are computed by combining the independent peaks from the omni-directional "all year" data. This is a conservative approach as the peak wave induced current may not occur at the same time as the peak flow current.

The combined seabed current for both 10- and 100 -year return periods are summarised in Table 3.

Table 3. Combined seabed current

\begin{tabular}{lll}
\hline Parameters & 10 -year & 100 -year \\
\hline Combined seabed current (m/s) & 1.90 & 2.70 \\
\hline
\end{tabular}

\subsubsection{Seawater density}

The seawater density adopted was $1,025 \mathrm{~kg} / \mathrm{m}^{3}$.

\subsubsection{Rock density}

The rock density adopted was $2,690 \mathrm{~kg} / \mathrm{m}^{3}$.

\subsection{Calculation summary}

\subsubsection{General}

The seabed preparation support pads were established as nominally $1 \mathrm{~m}$ thick elements to provide a controlled surface condition for support of the DCP pad footings at a level of -42 mLAT.

Preliminary calculations were undertaken to assess the material size for the granular fill forming the seabed preparation support pads which is able to re- 
sist self-scour along the straight edges of the hexagonal pad footing for the 10 -year return period cyclonic event without the DCP in-place and the 100year return period cyclonic event with the DCP inplace.

Calculations were also performed to compute the required material sizing in the 100 -year return period cyclonic event with the DCP in-place for the apices of the pad footings where flow velocities are locally enhanced. The local change in the flow at the apices causes an increase in the velocity and in the turbulence level, leading to an increase in the sediment transport capacity which may result in local scour of the seabed until an equilibrium state is reached. This identified the need for a local dedicated scour protection layer at the apices.

Although the rock sizing needed to resist the increased flow at the apices of the pad footing was computed, a realistic extent of the potential scour zone was not able to be readily quantified using analytical approaches In addition, the assumptions made at the preliminary calculation stage resulted in a conservative approximation of the flow enhancement with a commensurately conservative sizing for the dedicated scour protection.

Once installed, the distance between the near / far DCP legs and the adjacent SWP concrete caisson is $\sim 40 / 82 \mathrm{~m}$. As such, the influence of the SWP on the flow velocities around the DCP footings was expected to be minor and no enhancement to account for this effect was included in the preliminary analytical design calculations.

Eliminating conservatism in the preliminary scour protection design became a focus as the project progressed which introduced the need to use Computational Fluid Dynamics (CFD) modelling and Wave Tank Testing (WTT). This had the added benefit of explicitly assessing the influence of the SWP on the DCP (and vice versa), as discussed in Section 5.

\subsubsection{Calculation methodology}

The preliminary rock sizing required for the seabed preparation support material and the dedicated scour protection layer was calculated using Pilarczyk's method, as discussed in CIRIA (2007). The equation is given as:

$$
D_{n 50}=\frac{\Phi_{s c}}{\Delta} \frac{0.035}{\Psi_{c r}} k_{h} k_{s l}{ }^{-1} k_{t}{ }^{2} \frac{U^{2}}{2 g}
$$

where $\mathrm{D}_{\mathrm{n} 50}=$ median nominal diameter $(\mathrm{m}) ; \mathrm{D}_{50}=$ sieve diameter $(\mathrm{m}) ; \mathrm{D}_{\mathrm{n} 50}=0.84 \times \mathrm{D}_{50} ; \phi_{\mathrm{sc}}=$ stability correction factor; $\Delta=$ relative buoyant density of the protection element; $\Psi_{\mathrm{cr}}=$ critical mobility parameter of the protection element; $\mathrm{k}_{\mathrm{t}}=$ turbulence factor; $\mathrm{k}_{\mathrm{h}}=$ velocity profile factor; $\mathrm{k}_{\mathrm{sl}}=$ side slope factor; $\mathrm{U}=$ flow velocity $(\mathrm{m} / \mathrm{s})$; and $\mathrm{g}=$ gravity acceleration, $9.81 \mathrm{~m} / \mathrm{s}$.
The rock sizing determined for dedicated scour protection was based on applying a higher stability correction factor, $\phi_{\mathrm{sc}}$ than for the seabed preparation layer to represent the flow enhancement at the apices of the pad footings. A $\phi_{\mathrm{sc}}$ value of 0.75 and 1.5 was adopted for seabed preparation and supplementary scour protection, respectively, based on CIRIA (2007) recommendation for exposed edges of rip-rap and armourstone.

\subsubsection{Calculation results}

The calculated rock size required to resist self-scour prior to placement of the DCP (10-year return period design event), and the size required along the straight edges of the pad footings with the DCP in place (100-year return period event), are listed in Table 4.

The calculated rock size required at the apices of the pad footings under the 100 -year return period cyclonic event was considerably larger than that selected for the seabed preparation support pads, and as such represents a dedicated scour protection layer. The rock sizing for the dedicated scour protection material is listed in Table 5.

Table 4. Calculation results for seabed preparation

\begin{tabular}{llll}
\hline Seabed preparation & $\mathrm{D}_{\min }(\mathrm{m})$ & $\mathrm{D}_{50}(\mathrm{~m})$ & $\mathrm{D}_{\max }(\mathrm{m})$ \\
\hline 10 -year return period & 0.020 & 0.035 & 0.050 \\
100 -year return period & 0.050 & 0.085 & 0.120 \\
\hline
\end{tabular}

Table 5. Calculation results for scour protection

\begin{tabular}{llll}
\hline Scour protection & $\mathrm{D}_{\min }(\mathrm{m})$ & $\mathrm{D}_{50}(\mathrm{~m})$ & $\mathrm{D}_{\max }(\mathrm{m})$ \\
\hline 10-year return period & 0.050 & 0.085 & 0.120 \\
100-year return period & 0.120 & 0.200 & 0.290 \\
\hline
\end{tabular}

At this stage in the project, and to allow for some flexibility in anticipation of the scheduled CFD modelling and WTT described in Section 5, Particle Size Distributions (PSDs) for the seabed preparation and dedicated scour protection were established in order to progress initial discussions with potential seabed preparation Contractors. The adopted PSDs are shown in Figures 4 and 5 and were developed following the recommendations of CIRIA (2007) for wide grading.

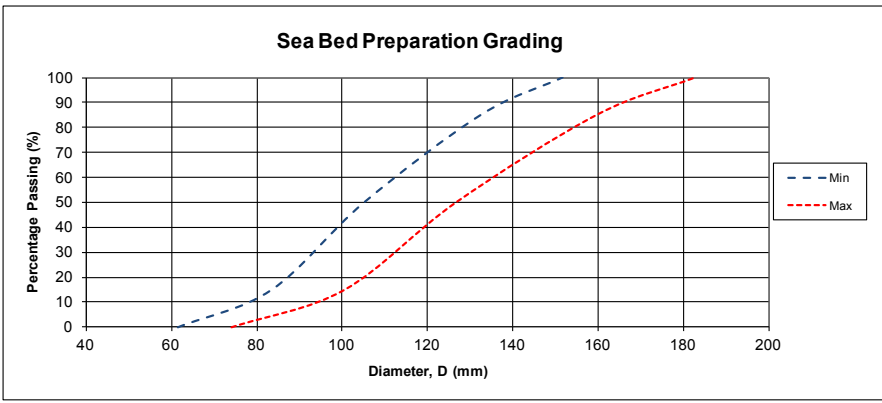

Figure 4. Rock size grading for seabed preparation 


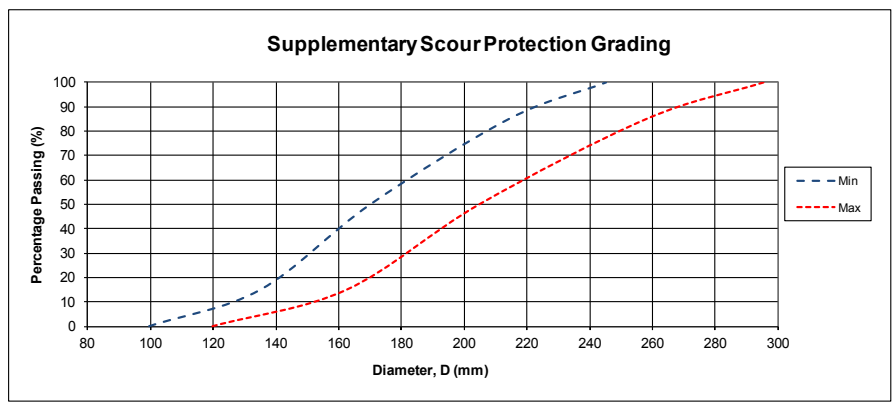

Figure 5. Rock size grading for dedicated scour protection

\subsection{Scour protection length}

\subsubsection{General philosophy}

The required scour protection length is defined in USACE (2011) as three times the total scour depth. The scour protection length is the horizontal distance from the edge of the footing, not including the slope length. The scour depth is calculated using the recommendations in Sumer \& Fredsoe (2002) and then compared to the potential scourable layer thickness based on the soil profiles.

\subsubsection{Scour depth}

The scour depth, $\mathrm{S}$ is calculated using equation 3.30 from Sumer \& Fredsoe (2002), which is reproduced below. This equation is valid for slender piles where $\mathrm{D} / \mathrm{L}<0.2$. Group pile effects were not considered given that the DCP legs are $42 \mathrm{~m}$ apart.

$$
\begin{aligned}
& A=0.03+\frac{3}{4} U_{c w}^{2.6} \\
& B=6 \exp \left(-4.7 U_{c w}\right) \\
& U_{c w}=\frac{U_{c}}{U_{c}+U_{m}} \\
& U_{c w}=\frac{U_{c}}{U_{c}+U_{m}} \\
& K C=\frac{U_{m} T_{w}}{D}
\end{aligned}
$$$$
\frac{S}{D}=\frac{S_{c}}{D}[1-\exp (-A(K C-B))] ; K C>B
$$

where $\mathrm{D}=$ pile diameter, $3.8 \mathrm{~m} ; \mathrm{S}_{\mathrm{c}}=$ scour depth in the case of the steady current alone, $S_{c} / D=2.7$ recommended for design purposes as maximum scour depth for the live-bed scour; $\mathrm{U}_{\mathrm{cw}}=$ velocity ratio (combined currents and waves); $\mathrm{U}_{\mathrm{c}}=$ flow velocity from currents; $\mathrm{Um}=$ flow velocity from waves; $\mathrm{KC}$

$=$ Keulegan-Carpenter number; $\mathrm{T}_{\mathrm{w}}=$ wave period;
$\mathrm{L}=$ wave length, calculated to be $270.2 \mathrm{~m}$ for 1 in 10 -year wave and $334.7 \mathrm{~m}$ for 1 in 100 -year wave.

The calculation outputs for the 10- and 100-year return period conditions are listed in Table 6 .

Table 6. Scour depth estimate summary

\begin{tabular}{lll} 
Return period & 10 -year & 100 -year \\
\hline $\mathrm{KC}$ & 4.093 & 7.427 \\
$\mathrm{U}_{\mathrm{cw}}$ & 0.419 & 0.367 \\
$\mathrm{~A}$ & 0.108 & 0.086 \\
$\mathrm{~B}$ & 0.836 & 1.067 \\
$\mathrm{~S}_{\mathrm{c}} / \mathrm{D}$ & 2.700 & 2.700 \\
$\mathrm{~S} / \mathrm{D}$ & 0.802 & 1.133 \\
$\mathrm{~S}(\mathrm{~m})$ & 3.050 & 4.300 \\
\hline
\end{tabular}

\subsubsection{Potential scourable layer thickness}

The soil profiles at the location of the DCP are predominantly a layer of carbonate sand above reef limestone. The thickness of the carbonate sand varies, with a typical depth below -43 mLAT of approximately $3 \mathrm{~m}$. Therefore for initial design concept conditions, with the in-situ carbonate sand left in place and covered with a nominally $1 \mathrm{~m}$ thick seabed preparation support layer, the maximum potential scourable layer thickness adopted was $3 \mathrm{~m}$ for all pad footings.

\subsubsection{Scour protection length}

From Table 6 , the calculated scour protection length is approximately $3 \times 3.05 \sim 9.2 \mathrm{~m}$ for 1 in 10 year condition and $3 \times 4.3 \sim 12.9 \mathrm{~m}$ for 1 in 100-year condition.

Taking into account the soil profile and the maximum potential thickness of the scourable layer, the length of the scour protection was recommended to be a minimum of $9 \mathrm{~m}$ from the edge of the pad footings in accordance with the design philosophy outlined in section 4.2.3.

\section{DESIGN DEVELOPMENT AND VALIDATION} In parallel with the preliminary calculations for sizing the granular material forming the seabed preparation and dedicated scour protection, design development required that the in-situ carbonate sand present primarily within the eastern half of the DCP footprint be removed to the upper surface of the underlying reef limestone.

The additional procurement requirements associated with obtaining a larger volume of seabed preparation material than originally anticipated challenged the team to find savings in both procurement of the required granular materials and offshore placement time. As a result, the design team decided to consider elimination of the separate scour protection layer altogether. 
The CFD modelling and WTT work performed to justify this decision are described below. Significant effort was expended to address the geotechnical and structural challenges introduced by this change e.g. the possibility of undulations in the seabed preparation pad surface which could result in local stress concentrations on the underside of the footing. Details of these calculations are beyond the scope of this paper.

\subsection{Computational fluid dynamics}

The CFD modelling undertaken to assess the peak amplified flow velocities around the DCP pad footings was performed by the Danish Hydraulics Institute (DHI) in two stages, using a scope of work prepared by Arup. The CFD model included both the DCP and SWP, as shown in Figure 6.

The first stage of the analysis was a screening study, performed to establish critical cases for the second stage detailed assessment. In the screening study only waves were modelled and applied in six directions around the platform perimeter. For the second stage analysis. Combined wave and current actions were applied in the most critical direction using 100-year return period cyclonic inputs.

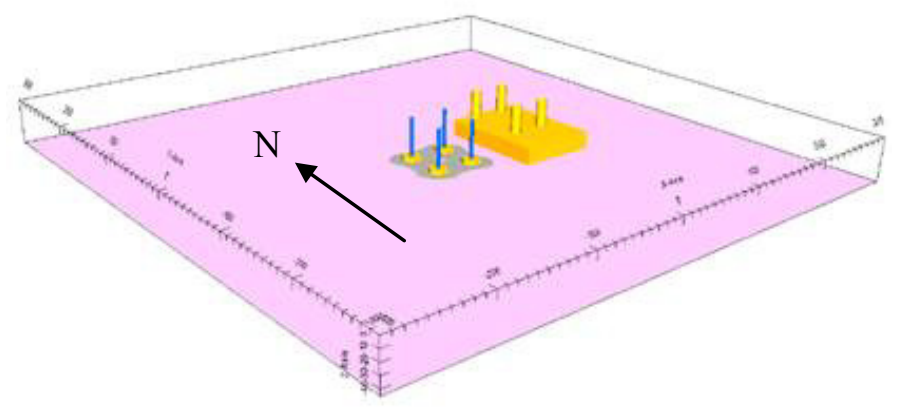

Figure 6. Computational fluid dynamics model set-up

For the case with the DCP in-place, the most critical storm direction which showed a maximum amplification of velocity was identified as North $(\mathrm{N})$ to South (S). This analysis indicated that a peak flow velocity of $3.7 \mathrm{~m} / \mathrm{s}$ occurs at the most exposed apices of the pad footings.

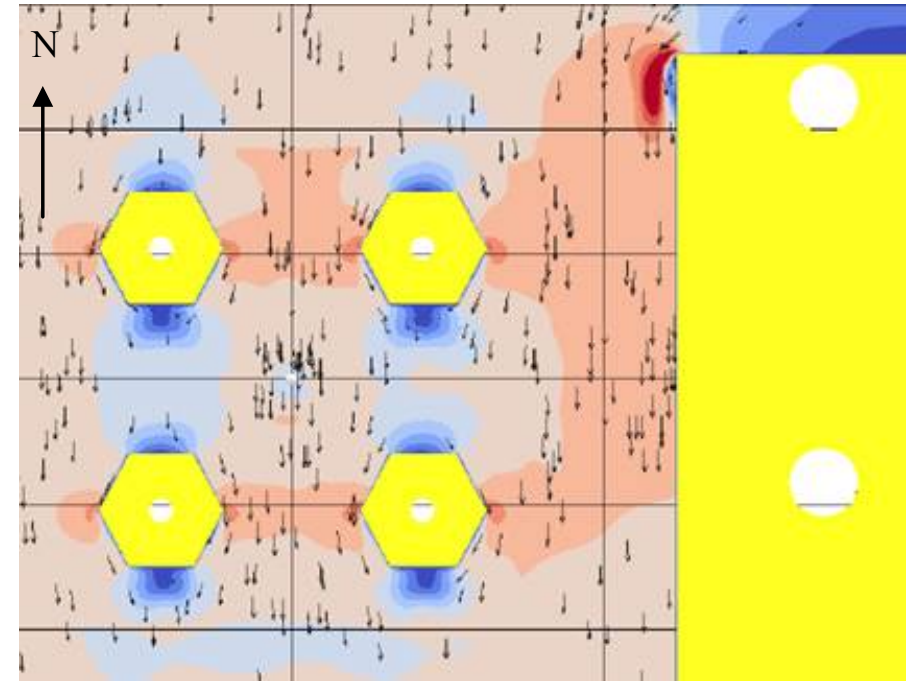

Figure 7. Sample Flow velocity field around SWP and DCP pad footings from CFD analysis for North to South storm

The maximum reported flow velocity of $3.7 \mathrm{~m} / \mathrm{s}$ was computed based on a 10-minute duration extreme wave condition for the 100 -year return period cyclonic event. Scour protection design equations are based on significant values and assuming a Rayleigh distribution of the wave heights, the significant flow velocity may be computed based on the ratio $\mathrm{H}_{\max } / \mathrm{H}_{\mathrm{s}}=1.43$ for the 10 -minute duration storm event. As such the significant flow velocity for calculation of the required sizing of granular material was computed to be $\sim 3.7 / 1.43=2.6 \mathrm{~m} / \mathrm{s}$. The associated rock sizing was calculated using the method described in Section 4.4.2. The design parameters and outputs are listed in Table 7.

Table 7. Design parameters and results

\begin{tabular}{ll}
\hline Return period & 100 -year \\
\hline $\mathrm{U}(\mathrm{m} / \mathrm{s})$ & 2.6 \\
$\phi_{\mathrm{sc}}$ & 0.75 \\
$\Delta$ & 1.62 \\
$\Psi_{\mathrm{cr}}$ & 0.035 \\
$\mathrm{k}_{\mathrm{h}}$ & 0.273 \\
$\mathrm{k}_{\mathrm{s}}-1$ & 1 \\
$\mathrm{k}_{\mathrm{t}}^{\mathrm{t}}$ & 1.5 \\
$\mathrm{D}_{50}(\mathrm{~m})$ & 0.075 \\
$\mathrm{w}_{50}(\mathrm{~kg})$ & 0.67 \\
\hline
\end{tabular}

The sizing presented in Table 7 accords with the PSD for the seabed preparation material presented in Figure 4 selected during the preliminary design phase. As such, no alterations were required to the material selected for use as backfill to the seabed excavation and construction of the seabed preparation support pads as a result of the CFD modelling results.

In addition, the peak flow velocity calculated in the CFD modelling and the associated required material sizing shown in Table 7 allowed the dedicated scour protection material (PSD provided in Figure 5) to be deleted, representing a large saving to the pro- 
ject in material procurement, vessel modification and offshore construction time.

\subsection{Wave tank testing}

In order to validate the results of the CFD modelling, DHI was engaged to perform WTT using a scope of work prepared by Arup. The 100-year return period cyclonic storm was simulated from six directions (identical to those used in the screening study) with flow velocity measurement probes installed (at prototype scale) $1.4 \mathrm{~m}$ from the face of the pad footings and at a height of $1.4 \mathrm{~m}$ above the surface of the seabed preparation support pad. This position represented the closest practical location for placement of the probe tip. The wave tank model of the DCP and SWP is shown in Figure 8, with the location of the flow velocity measurement probe locations shown in Figure 9.

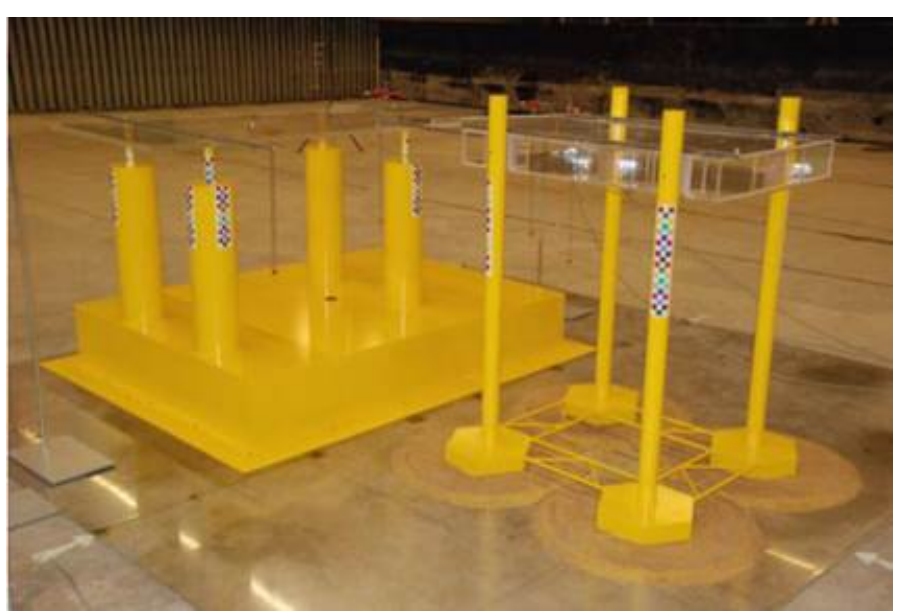

Figure 8. Wave tank testing model set-up

Key: flow velocity probe measurement point

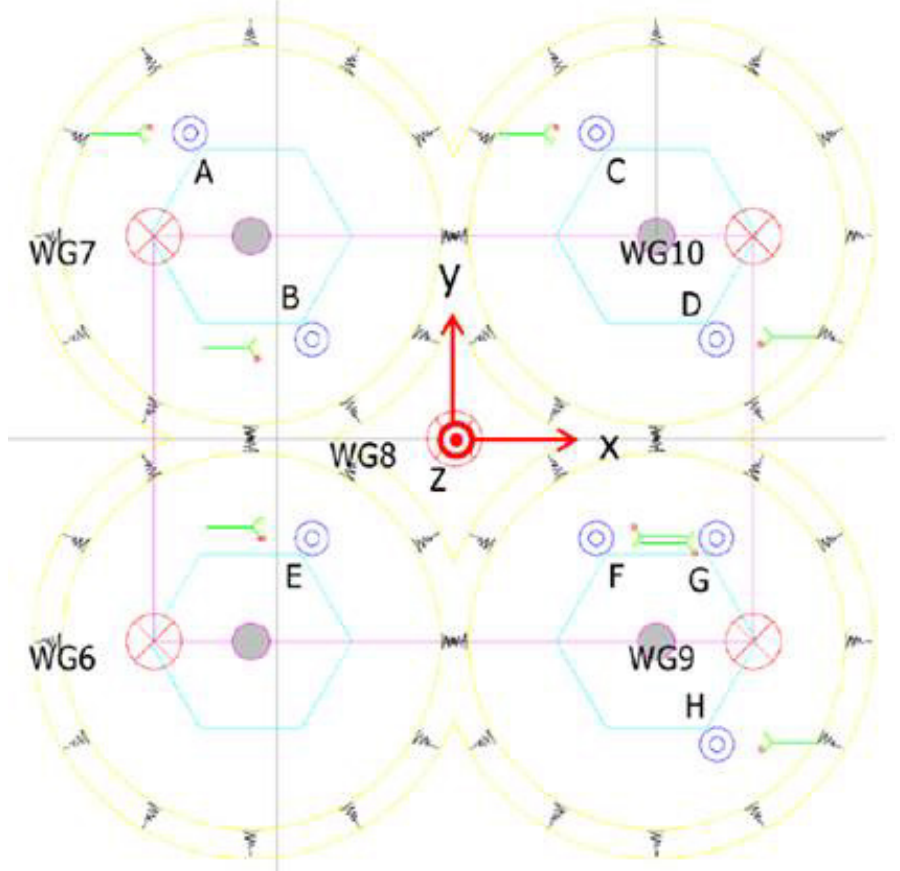

Figure 9. Flow velocity probe locations for wave tank testing
The peak velocity measured during the 3-hour duration (prototype scale) 100-year return period cyclonic storm event was $4.7 \mathrm{~m} / \mathrm{s}$. Assuming a Rayleigh distribution of the wave heights, the significant flow velocity (relevant to scour computations) was computed based on the ratio $\mathrm{H}_{\max } / \mathrm{H}_{\mathrm{s}}=1.87$ for the 3-hour duration storm event, such that the associated significant flow velocity was computed to be $\sim 4.7 / 1.87=2.5 \mathrm{~m} / \mathrm{s}$. This is in very close agreement with the result of $2.6 \mathrm{~m} / \mathrm{s}$ obtained from the CFD modelling performed.

\subsection{Design Validation}

Based on the flow velocity outputs from the CFD modelling and WTT, it was concluded that the requirement for supplementary scour protection could be eliminated i.e. the rock grading proposed for the seabed preparation in Figure 4 was deemed sufficient.

\section{CONSTRUCTION}

Seabed preparation activities for the DCP consisted of excavation of the in-situ carbonate sand to the upper surface of the reef limestone, removal of the reef limestone outcrop across the western side of the excavation footprint, and replacement with engineered seabed preparation material to form four elevated foundation pads for placement of the DCP. A 3-dimensional (3-D) image of the completed excavation, visualised using multi-beam echo sounding (MBES) is shown in Figure 10.

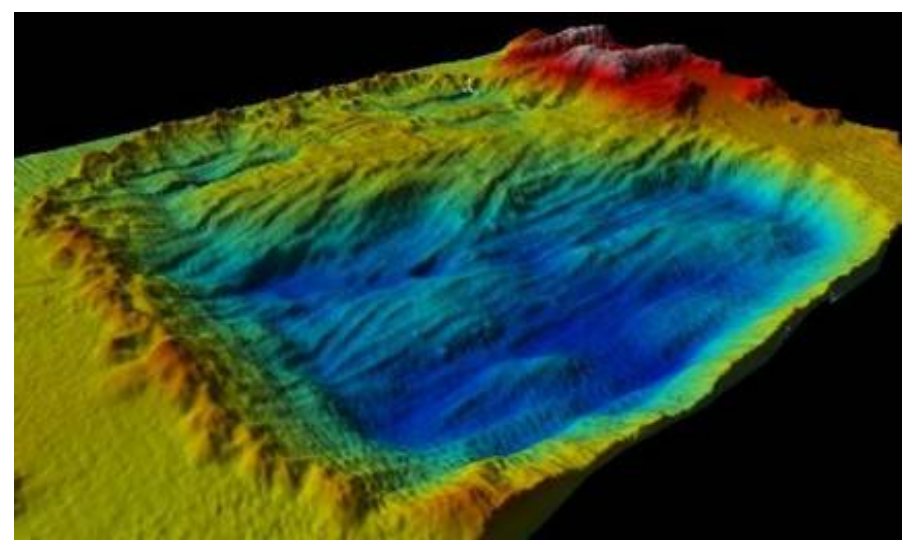

Figure 10. 3-D excavated seabed profile visualised using multibeam echo sounding

Following the completion of excavation, seabed preparation material was initially used as bulk backfill to the general seabed level. It was then used to carefully prepare four seabed preparation support pads at a target elevation which had strict tolerances on the global tilt and the height of any local surface undulations. 
The material properties of the seabed preparation material were tested on a regular interval during production to conform compliance with a set of acceptance criteria specified by Arup. With respect to the scour resistance capabilities of the seabed preparation material, the criterion to be confirmed was the material's particle density. This was adopted as $2,690 \mathrm{~kg} / \mathrm{m}^{3}$ in design and was validated to range between 2,850 and $2,950 \mathrm{~kg} / \mathrm{m}^{3}$ for the selected seabed preparation material, with an average of $2,910 \mathrm{~kg} / \mathrm{m}^{3}$.

A 3-D image of the backfilling and seabed preparation pad footing construction in progress, visualised using MBES is shown in Figure 11.

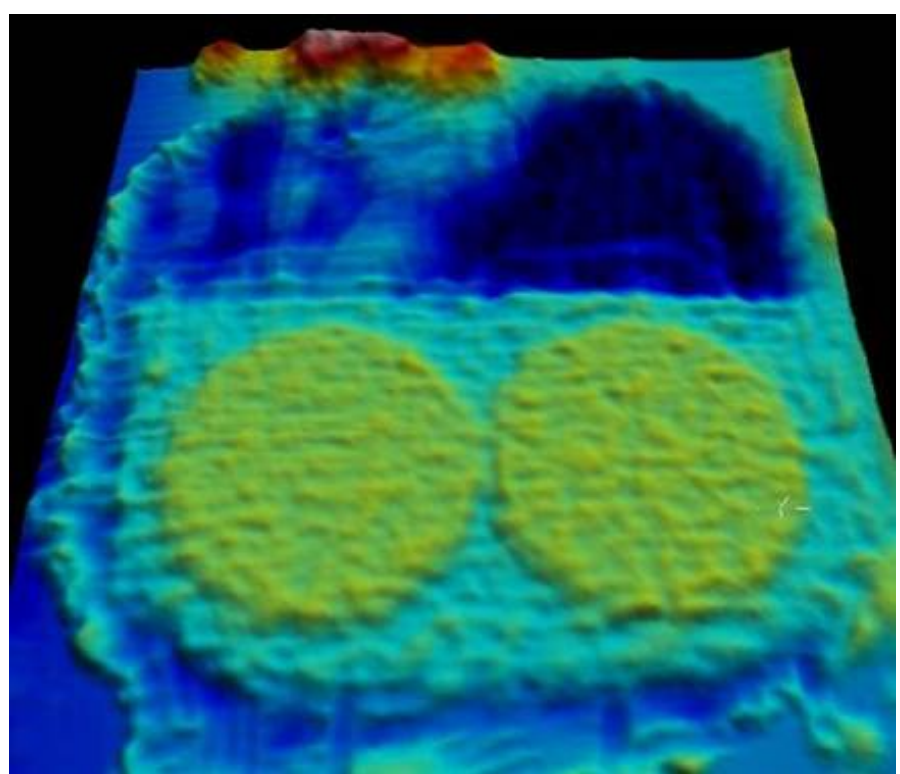

Figure 11. Backfill progress visualised using multi-beam echo sounding

An actual image of the pad footing placed upon on of the seabed preparation support pads is shown in Figure 12.

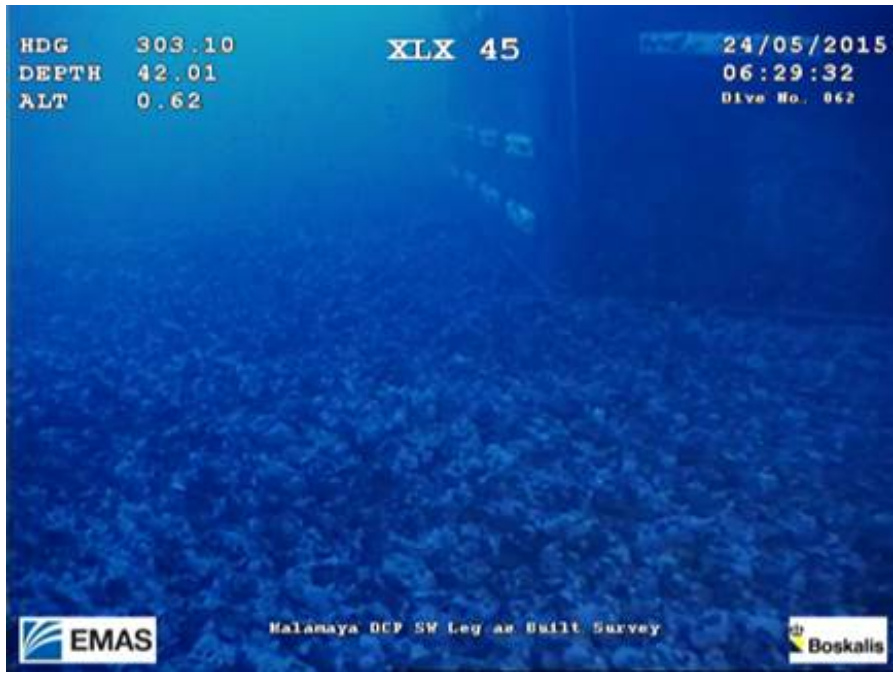

Figure 12. Pad footing placed upon seabed preparation

\section{CONCLUSION}

The preliminary work performed on the scour protection design established conservative grading curves for both the seabed preparation material and dedicated scour protection layer to allow initial discussions with seabed preparation Contractors to be progressed.

The design development that occurred subsequent to the completion of the preliminary design allowed conservatisms in the scour protection design to be eliminated. This resulted in savings for the project in material procurement, avoiding modifications to the Contractor's vessel, and a reduction in offshore working time.

The use of advanced numerical modelling (CFD), validated through scale model testing (WTT) and supported by in-depth structural and geotechnical engineering calculations, was used to justify the use of large sized material beneath the pad footing foundation system. As a result, in-place (temporary) stability of the DCP platform was achieved in less than 2 days from arrival at site, with no follow on work required for the placement of dedicated scour protection. This allowed full attention to be placed on final weld out of the barge to leg connections.

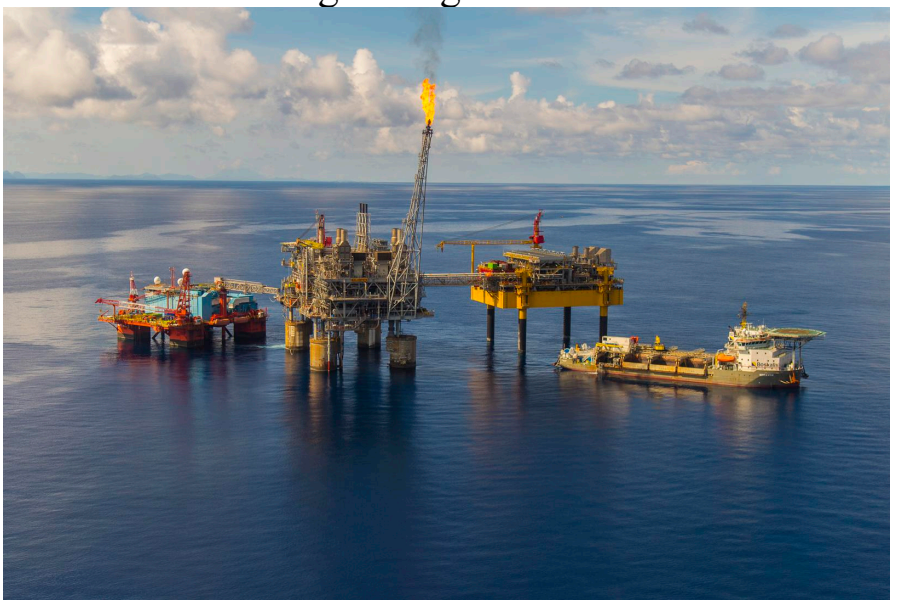

Figure 13. The Malampaya DCP (right) bridge-linked to the SWP

\section{ACKNOWLEDGMENTS}

The authors would like to thank SPEX who provided an environment for the team to succeed. We also thank Fluor (Topsides Designer), who enthusiastically supported Arup as an integrated member of the Malampaya DCP project team.

\section{REFERENCES}

CIRIA, CUR, CETMEF (2007). The Rock Manual. The use of rock in hydraulic engineering ( $2^{\text {nd }}$ edition). C683, CIRIA, London.

Sumer \& Fredsoe (2002). The Mechanics of Scour in the Marine Environment, World Scientific, Singapore.

USACE (2011). Coastal Engineering Manual, EM 1110-2-1100 Part VI. 